\title{
Oficina pedagógica na construção do conhecimento em Geografia física: Um relato de experiência
}

\author{
Educational workshop in the construction of knowledge in Physical Geography: \\ A report of experience
}

SANTOS, A, C.

ariel.costa.geo@gmail.com

\begin{abstract}
Resumo
Apresentamos como objetivo da pesquisa refletir sobre a importância das oficinas no ensino de Geografia física nos dias atuais, e como a adição de novas práticas de ensino pode auxiliar neste processo. O presente trabalho foi realizado com os alunos do quarto ano do curso de licenciatura em Geografia, da Universidade Federal de Mato Grosso, Campus de Rondonópolis. Para o desenvolvimento da pesquisa, foi feito um levantamento teórico metodológico a fim de subsidiar o estudo proposto abordando a magnitude da preservação da mata ciliar próximo aos rios, e para exemplificar o que foi falado dentro da sala de aula, foi elaborada uma maquete com o intuito de demonstrar a importância conservação desse ecossistema. Ao fim desta experiência concluise que a oficina pedagógica facilita o ensino na Geografia Física.
\end{abstract}

Palavras-chaves: Ensino de Geografia física, Oficinas pedagógicas, Recursos didáticos.

\begin{abstract}
We present the research objective is to reflect on the importance of the workshops on the teaching of physical geography in the present day, and as the addition of new teaching practices can assist in this process. The present work was carried out with the students of the fourth year of the degree course in geography, from the Federal University of Mato Grosso, Campus of Rondonópolis. For the development of research, was made a theoretical survey methodology in order to subsidize the study proposed addressing the magnitude of the preservation of riparian areas close to rivers, and to illustrate what was spoken in the classroom, a model has been developed in order to demonstrate the importance conservation of this ecosystem. At the end of this experiment concluded that the pedagogical workshop facilitates the teaching in physical geography.
\end{abstract}

Keywords: teaching of physical geography, educational workshops, teaching resource.

\section{INTRODUÇÃO}

Trilhar os caminhos da análise, pesquisa e construção da Geografia física no sistema de ensino que trabalha com a descrição dos fatos não tem sido tarefa fácil nos dias atuais.

O ensino deve ser um processo de relação constante entre professor e aluno, caracterizado pela busca interativa de novas formas de aprendizagem que ajudem a tornar a sala de aula um ambiente onde o educando sinta o prazer de estudar, ao mesmo

\footnotetext{
${ }^{1}$ Ariel Costa dos Santos, Departamento de Geografia, LAGEF-Laboratório de geografia física, Cuiabá-MT, Brasil.
} 
tempo em que seja incentivado à pesquisa, tornando-o dessa forma um investigador na busca conjunta pelo conhecimento, e podendo agir de forma racional na sociedade (MUNIZ e SILVA, 2012).

Sabendo dessa interação que deve ocorrer entre o educador e o educando, o avanço tecnológico de nossos dias fornece uma gama de possibilidades para os educadores, contudo, esses recursos não estão disponíveis de maneira equitativa em todas as escolas. Muitos centros públicos de ensino sofrem a carência desses equipamentos e vários professores utilizam-se desse argumento como justificativa para continuarem com suas aulas tradicionais pautadas apenas no livro didático, lousa e giz (COSTA e CARVALHO, 2013).

Embora haja carência de equipamentos nas escolas, sabemos que o uso de recursos didáticos para além dos tradicionais na ciência geográfica auxilia no processo de ensino-aprendizagem do aluno, pois se torna possível ultrapassar as barreiras da geografia mais analítica interpretativa voltada apenas para a descrição de fatores, para a formação do aluno mais critico, visto as constantes mudanças geradas pelo modo de produção capitalista que vem ocorrendo na sociedade, mudanças essas que vem cada vez mais deteriorando o meio ambiente.

Para Muniz e Silva (2009) o recurso didático, não tem a capacidade de garantir inteiramente a aprendizagem do aluno, mas desperta nesse um interesse maior na aula, pois oferece ao educando a oportunidade de trabalhar com elementos que o permitam ser protagonista na construção do conhecimento. Dessa forma para melhor compreensão desses fatores em sala de aula, o conhecimento geográfico e pedagógico precisa estar junto, visando à formação do aluno.

A principal meta das oficinas pedagógicas é desenvolver atividades e material didático para atrair a atenção do aluno para a sala de aula, para os conteúdos e aula de campo, com a intenção de deixar as aulas mais atrativas, dinâmicas e participativas, porém, preservando o diálogo entre educando e educador.

\section{METODOLOGIA}

A oficina foi realizada em uma turma de quinze alunos do quarto ano do curso de licenciatura plena em Geografia da Universidade Federal de Mato Grosso (UFMT) 
campus Universitário de Rondonópolis, a mesma teve duração de uma hora. Durante a realização da oficina pedagógica, utilizou-se uma aula expositiva e dialogada, e para exemplificar o que foi falado durante a aula, foi elaborada uma maquete representando uma bacia hidrográfica, visando mostrar aos alunos a importância da preservação da mata ciliar que são encontradas próximo aos rios.

\section{RESULTADOS E DISCUSSÕES}

O ponto de partida para este trabalho foi à sala de aula, pois é nela que se manifestam as dificuldades dos alunos de aprender e do professor de ensinar conteúdos mais específicos da Geografia física.

No dizer de Nascimento et al. (2015) no ensino de Geografia, é perceptível que as oficinas pedagógicas contribuem significativamente para o processo de ensinoaprendizagem em diversos temas, principalmente através da construção de recursos didáticos como mapas, croquis, ilustrações, de textos, dentre outros que a posteriori servirá como fonte de aprendizagem.

Conforme Mocellin (2014) dentro das instituições de ensino é preciso encontrar meios para que os alunos entendam os fenômenos naturais e consequentemente, venham a desenvolver senso critico diante desta realidade, assim efetivando a educação ambiental em sua vivência.

A maquete nesse contexto se apresenta como um recurso didático que pode subsidiar no processo de ensino-aprendizagem do aluno.

Conforme Muniz e Silva (2012, p. 66), ao tratar da importância da maquete na ciência geográfica, destacam que:

As maquetes se apresentam como uma importante ferramenta para o ensino da Geografia, pois simulam uma forma de representação tridimensional do espaço, em grande escala cartográfica que não distorce a realidade. Além disso, propiciam uma identificação do aluno com a realidade demonstrada, uma vez que trabalham com imagens icônicas, ou seja, com símbolos próprios de cada cultura, utilizados para representar os elementos contidos nas maquetes. 
Dessa forma, as maquetes despertam nos alunos a curiosidade em investigar o espaço vivido, interpretá-lo e contextualizar a Geografia do lugar, promovendo o interesse da participação nas mudanças da sociedade. Propícia a valorização local e a solução de problemas, desde o espaço físico ao social, ligando o ensino da disciplina ao cotidiano do aluno, pois possibilita mostrar a organização e a ocupação do espaço, além da interação com o meio representado na maquete (PINTANO e ROQUÉ, 2015).

Durante a oficina pedagógica, o objetivo da maquete (Figura 01) foi mostrar aos alunos o processo de lavagem do solo que leva ao assoreamento dos rios em áreas desmatadas. Nota-se na figura exposta abaixo que a mesma apresenta a margem esquerda com poucas vegetações, simbolizando o desmatamento, e a margem direita com vegetação acompanhando o canal.

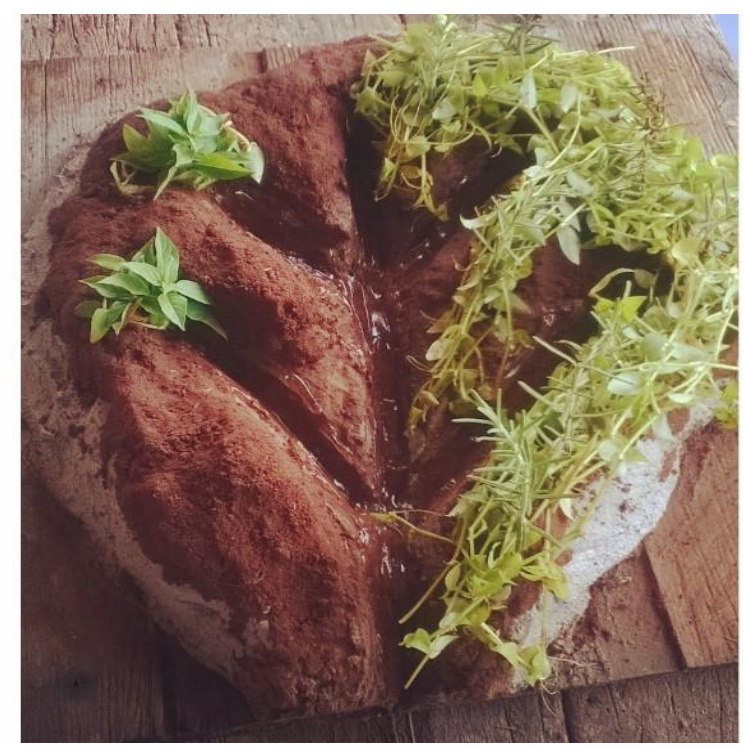

Figura 01: Bacia Hidrográfica Fonte: SANTOS, 2015.

Para exemplificar os danos que o desmatamento pode causar nos rios, foi feito uma comparação dentro da sala de aula, em um regador com água, foi derramado no lado do rio onde possuía vegetação, simulando uma possível chuva, e notou-se que a água, pouco escoava, e saia em um teor mais limpo, deixando claro aos alunos que a preservação da vegetação em torno dos rios possibilita que espécies, tanto da fauna quanto da flora se desenvolvam naquelas localidades garantindo a biodiversidade. Além disso, a vegetação existente ao longo dos rios funciona como um obstáculo natural ao escoamento das águas, que ficam retidas e são absorvidas, em grande parte, pela mata, 
evitando que uma quantidade exagerada de partículas sólidas sejam arrastadas e depositadas nos leitos dos rios.

Foi possível notar a partir dessa experiência com vegetação, que não ocorreu deslizamento de terra para dentro do rio, em contrapartida quando a água foi derramada na margem do rio onde a mata ciliar foi desmatada constatou-se que sem a mata ciliar ocorre à erosão das margens levando terra pra dentro do rio, e consequentemente assoreando o mesmo.

Conforme Bozza et al. (2006, p. 2),

\begin{abstract}
$\mathrm{O}$ desmatamento das matas ciliares resulta no assoreamento do rio. Como a mata ciliar tem por principal função proteger o solo contra erosões, a ausência desta deixa o solo desprotegido, ficando sujeito a erosões. Com a chuva, a terra é desgastada, indo para o rio, o qual fica assoreado, tendendo a ficar cada vez mais raso. Isso também diminui a qualidade da água, afetando os ecossistemas que habitam o rio, acarretando no desequilíbrio das relações ecológicas da região.
\end{abstract}

Neste contexto a preservação da vegetação ao longo dos rios é fundamental para um adequado e equilibrado funcionamento dos ecossistemas e para a manutenção da diversidade biológica. As vegetações também exercem funções significativas no controle da erosão, da desertificação, da qualidade da água e do sequestro do carbono atmosférico, além de constituírem espaço para desenvolvimento de atividades sociais, ambientais e econômicas (BARCELLAR, 2005).

Este processo de degradação das formações ciliares, além de desrespeitar a legislação, que torna obrigatória a preservação das mesmas, resulta em vários problemas ambientais. As matas ciliares funcionam como filtros, retendo defensivos agrícolas, poluentes e sedimentos que seriam transportados para os cursos d'água, afetando diretamente a quantidade e a qualidade da água e consequentemente a fauna aquática e a população humana. São importantes também como corredores ecológicos, ligando fragmentos florestais e, portanto, facilitando o deslocamento da fauna e o fluxo gênico entre as populações de espécies animais e vegetais. Em regiões com topografia acidentada, exercem a proteção do solo contra os processos erosivos (BOZZA, et al. 2006). 
Ao fim da experiência com a maquete, notou-se que o lado do rio onde não possuía vegetação perdeu muito solo, em contrapartida o lado oposto, com vegetação encontra-se protegido. $\mathrm{O}$ uso da maquete foi de grande importância para despertar nos alunos o interesse pela preservação da vegetação próximo a rios.

A oficina realizada em sala foi muito produtiva. De maneira geral, a oficina transcorreu dentro da normalidade, buscando estratégias pedagógicas que possibilitassem a conexão entre a teoria e a prática.

\section{CONSIDERAÇÕES FINAIS}

A oficina pedagógica é uma forma de fortalecer conhecimento, com foco na ação prática, sem perder de vista, porém, a base teórica.

Diante do exposto, a associação entre teoria e prática é sempre um desafio, porém, pode ser vencido. Para que essas barreiras sejam superadas um dos caminhos possíveis é a construção de estratégias de integração entre os conhecimentos teóricos e práticas, o que, essencialmente, caracteriza as oficinas pedagógicas.

A experiência adquirida na oficina citada é muito importante para a formação do futuro professor, pois, a mesma possibilita uma formação contínua do docente, além de auxiliar os alunos para o desenvolvimento da construção criativa e coletiva do conhecimento.

Dessa maneira, foi possível notar que quando o professor busca novas estratégias para ser aplicadas no processo de ensino-aprendizagem, o mesmo torna-se atrativo, com isso, surge um novo tipo de comunicação entre professores e alunos, que vai além daquele estabelecido apenas pela leitura e o diálogo.

Conclui ao fim desse trabalho, que as diferentes linguagens de ensino são importantes ferramentas no processo de aprendizagem da Geografia Física, apresentando-se como uma forma de resgatar nos alunos a vontade e o prazer pela ciência geográfica, desprendendo-a de verdades absolutas. 


\section{REFERÊNCIAS}

COSTA, Aline de Oliveira, CARVALHO; Aparecida de Moraes. O uso da maquete como instrumento no Ensino de Geografia. $5^{\circ}$ Congresso Internacional de Educação pesquisa e gestão. Ponta Grossa-PR, 2013.

BACELLAR, L.A.P. O papel das florestas no regime hidrológico de bacias hidrográficas.

http://jararaca.ufsm.br/websites/deaer/download/VIVIEN/Texto06/exartigorevisao.pdf (2016).

BOZZA, André Nogueira, et. al. Conscientização sobre a importância da mata ciliar realizada com alunos do ensino fundamental da escola sistema educacional realidade, Campinas-SP. Disponível em: <http://www.enapet.ufsc.br/anais/ Último acesso em: 29 de julho de 2016.

MOCELliN, Giani Motin. Conscientização da Importância da Mata Ciliar no Ensino Fundamental na Região Rural do Município de Colombo-PR. MEDIANEIRA, 2014. (Especialização em ensino de ciências)

NASCIMENTO, Aliery Araújo et al. Oficinas Pedagógicas no ensino de Geografia: (RE) Construção do Conhecimento Geográfico Escolar. IV Encontro de iniciação a docência da UFG. Goiás, 2013.

PITANO, Sandro de Castro; ROQUÉ, Bianca Beatriz. O uso de maquetes no processo de ensino-aprendizagem segundo licenciandos em Geografia. Educação Unisinos, v. 19, n. 2, p. 273-282, 2015.

SILVA, Vládia da; MUNIZ, Alexsandra Maria Vieira. A geografia escolar e os recursos didáticos: 0 uso das maquetes no ensino aprendizagem da geografia. Geosaberes, Fortaleza, v. 3, n. 5, p. 62-68, 2009. 2012

Recebido em: 14/08/2016

Aceito para publicação em: 01/10/2016 